\title{
Oleanolic Acid Induces Apoptosis and Necrosis in LO2 Cells
}

\author{
QINGWEN XIAO'1, YUANFU LU² AND XIUPING CHEN ${ }^{1,2^{*}}$
}

${ }^{1}$ State Key Laboratory of Quality Research in Chinese Medicine, Institute of Chinese Medical Sciences, University of Macau, Macau, China, ${ }^{2}$ Key Lab for Pharmacology of Ministry of Education, Department of Pharmacology, Zunyi Medical University, Zunyi, 563003, China

Xiao et al.: Oleanolic acid-induced cell death

This study mainly focused on the evaluation of cytotoxicity of oleanolic acid on normal human hepatic cells. Normal human hepatic cells were exposed to different concentrations of oleanolic acid and the results demonstrated that oleanolic acid induced cell death in a concentration- and time-dependent manner in LO2 cells. Low concentration of oleanolic acid $(40 \mu \mathrm{M})$ induced apoptosis. Cleavage of caspase 3/7/9 and decrease of mitochondrial membrane potential was detected in normal human hepatic cells. While high concentration of oleanolic acid $(80 \mu \mathrm{M})$ caused necrosis without producing cleavage of caspase 3/7/9 or DNA fragmentation. Both flow cytometry and PI staining detected necrotic cells. In addition, both low and high concentrations of oleanolic acid had no effect on the generation of intracellular reactive oxygen species. Present data showed that oleanolic acid could induce apoptosis and necrosis in normal human hepatic cells. Oleanolic acid might be a potential hepatotoxin at high dosage. 
Drug-induced liver injury is caused by an array of prescription medications, as well as herbal and dietary supplements ${ }^{[1]}$. Consumers commonly believe that the traditional Chinese medicines (TCM) labeled as natural are always safe and of benefit to health. Therefore, their adverse events and toxicity are often ignored ${ }^{[2]}$. Documented data indicated that TCM has acute and/ or chronic effects on heart, kidney, lung and liver when over-dosage was administrated ${ }^{[3,4]}$. TCM-induced liver injury frequently develops in cases of excessive or inappropriate use. Usually, this kind of liver injury is self-limiting, but it sometimes leads to serious complications, such as liver cirrhosis, acute liver failure and even death, unless a liver transplantation is performed $^{[5]}$. More and more attention has been paid to TCM-induced liver injury in recent years ${ }^{[4,6]}$. Oleanolic acid (OA, 3 $\beta$-hydroxyolean-12-en-28-oic acid) is a ubiquitous pentacyclic triterpenoid in many plant species and medicinal herbs. Naturally, OA exists either as a free acid or as an aglycone precursor for triterpenoid saponins ${ }^{[7]}$. OA has been widely investigated for more than half a century and documented data demonstrated that $\mathrm{OA}$ and its derivatives possessed multiple pharmacological activities, such as anticancer ${ }^{[8,9]}$, antidiabetic $^{[10,11]}$, antiinflammatory ${ }^{[12]}$, antiviral ${ }^{[13]}$, antioxidant, antiallergic and antimicrobial ${ }^{[14]}$. Especially, its hepatoprotective effect has been widely studied. OA has been found to protect liver damage and dysfunction. A study examined the effect of OA on acetaminophen (AA)-induced acute liver injury in mice and the mechanism of protection and reported that OA pretreatment resulted in an increased urinary excretion of AA-glucuronide and a decreased biliary excretion of AA-GSH. Based on this mechanism, OA decreased serum activities of alanine aminotransferase and sorbitol dehydrogenase and induced depletion in liver GSH content, thus protecting liver from injury ${ }^{[15]}$. Another study demonstrated for the first time that neonatal intake of OA attenuated the subsequent development of high fructose diet-induced non-alcoholic fatty liver disease (NAFLD) in rats by reducing hepatic lipid storage, terminal liver masses and hepatic histomorphological changes associated with NAFLD. They concluded that dietary supplementation with OA in the neonatal phase of development potentially programs for

*Address for correspondence

E-mail: xpchen@um.edu.mo

March-April 2020 hepatoprotection against the development of NAFLD in adult life ${ }^{[16]}$.

The prevalence of hepatitis in China is high. As early as in 1970 s, OA has been approved and prescribed clinically for the adjunctive treatment of acute and chronic hepatitis. Though the hepatoprotective effect of OA has been well established, a recent study showed that repeated oral administration of $\mathrm{OA}$ induced cholestatic liver injury in mice ${ }^{[17]}$ and OA altered bile acid homeostasis and produced cholestatic liver injury in $\mathrm{C} 57$ mice $^{[18]}$. Thus, OA is effective in protecting against various hepatotoxicants at low dosages while higher dosages and long-term application could produce liver injury ${ }^{[19]}$. These observation provided evidence that OA could also be toxic to liver. Cell death is not only a fundamental cellular event during development, but also plays an important role in various kinds of pathological process. Hepatocyte, the main components of the liver is especially vulnerable to injury due to its central role in xenobiotic metabolism including drugs and alcohol ${ }^{[20]}$. Severe injury to hepatocyte is frequently accompanied by cell death, which is typically driven by apoptosis. However, necrotic cell death in hepatocytes is also common.

In this study, the cytotoxicity of OA was explored on normal human hepatic (LO2) cell line. OA was found to be cytotoxic to LO2 cells and could induce both apoptosis and necrosis depending on different concentrations. OA ( $>97 \%$ Sigma-Aldrich, Darmstadt, Germany) was dissolved in dimethyl sulfoxide (DMSO) to prepare a $10 \mathrm{mM}$ stock solution and stored at $-20^{\circ}$. Dulbecco's modified Eagle's medium (DMEM), fetal bovine serum (FBS), bovine serum albumin (BSA), phosphatebuffered saline (PBS), penicillin-streptomycin (PS), and $0.25 \%(\mathrm{w} / \mathrm{v})$ trypsin/EDTA were obtained from Life Technologies/Gibco Laboratories (Grand Island, NY, USA). All antibodies were purchased from Cell Signaling Technology (Beverly, MA, USA). 5,5',6,6'-tetrachloro-1,1',3,3'-tetraethylbenzimidazo lylcarbocyanine iodide (JC-1) kit, propidium iodide

This is an open access article distributed under the terms of the Creative Commons Attribution-NonCommercial-ShareAlike 3.0 License, which allows others to remix, tweak, and build upon the work non-commercially, as long as the author is credited and the new creations are licensed under the identical terms

Accepted 19 January 2020 Revised 20 Decemebr 2019 Received 05 August 2019 Indian J Pharm Sci 2020;82(2):361-368 
(PI), Hoechst 33342 and reactive oxygen species assay kit were purchased from Beyotime Institute of Biotechnology (Haimen, China). LO2 cells (Cell Bank of the Chinese Academy of Sciences, Shanghai, China) were cultured in DMEM supplemented with 10\% heat-inactivated FBS. The cell culture condition were maintained at $37^{\circ}$ under an atmosphere of $5 \% \mathrm{CO}_{2}$ in an incubator.

Cell viability was determined using the MTT assay. Briefly, cells were seeded in 96-well plates and treated with or without a series of concentrations of OA for 6 or $24 \mathrm{~h}$. Then cells were cultured in MTT-containing DMEM medium $(1 \mathrm{mg} / \mathrm{ml})$ for another $4 \mathrm{~h}$. Hundred microlitres of DMSO was added to each well and the absorbance at $570 \mathrm{~nm}$ was recorded using a FlexStation 3 Benchtop Multi-Mode Microplate Reader (Molecular Devices, Sunnyvale, CA). The intracellular ATP levels were measured using CellTiter-Glo ${ }^{\mathrm{TM}}$ luminescent cell viability assay (Promega) following the manufacturer's instructions. Cells $\left(1 \times 10^{5}\right)$ were seeded in 12-well plates and treated with $\mathrm{OA}$ for $24 \mathrm{~h}$. The morphological changes of cells were observed with IN Cell Analyzer 2000 (GE Healthcare, Little Chalfont, Buckinghamshire, UK). Firstly, the plate was equilibrated at room temperature for $30 \mathrm{~min}$ after OA treatment. Then CellTiter-Glo ${ }^{\circledR}$ Reagent equal to the volume of cell culture medium present in each well was added. The contents were mixed for $2 \mathrm{~min}$ on an orbital shaker to induce cell lysis. Finally, luminescence was recorded.

Effect of OA on apoptosis was determined using human Annexin V (PE)/7-AAD detection kit (BD Biosciences, San Jose, CA, USA) according to the manufacturer's instructions. In brief, cells $\left(2.5 \times 10^{5}\right)$ were seeded in 6 -well plates and culture for overnight. Then cells were treated with different concentrations of OA, and harvested at predetermined time periods. After incubating with binding buffer containing Annexin V/7-AAD for $15 \mathrm{~min}$, the cell samples (at least $1 \times 10^{4}$ cells) were immediately analyzed by flow cytometry using a FACS Canto ${ }^{\mathrm{TM}}$ system (BD Biosciences). After treatment with OA treatment for 2 or $4 \mathrm{~h}, \mathrm{LO} 2$ cells were stained with 2',7'-dichlorofluorescindiacetate $\left(\mathrm{DCFH}_{2}-\mathrm{DA}, 10 \mu \mathrm{M}\right)$ for $30 \mathrm{~min}$ at $37^{\circ}$. After washing twice with PBS, the fluorescence was analyzed immediately in a FACScan ${ }^{\mathrm{TM}}$ flow cytometer (BD Biosciences) using the FITC channel. At least $1 \times 10^{4}$ cells were collected in each sample. LO2 cells were treated with different concentrations of OA for 6 or $12 \mathrm{~h}$ followed by JC- 1 staining $(10 \mu \mathrm{g} / \mathrm{ml})$ for 30 min at 37 in the dark. Fluorescence was observed with IN Cell Analyzer 2000.

Proteins were extracted after OA treatment and the content was determined using BCA protein assay kit (Pierce Biotechnology). Equal amounts of proteins $(30 \mu \mathrm{g})$ were separated by SDS-PAGEgel electrophoresis and transferred to PVDF membranes (Amersham Biosciences, Little Chalfont, Buckinghamshire, UK). Blocking the membranes with $5 \%$ nonfat milk in Tris buffered saline (TBS)-Tween 20 (Tris- $\mathrm{HCl}$ $20 \mathrm{mM}, \mathrm{NaCl} 137 \mathrm{mM}, 0.1 \%$ Tween, $\mathrm{pH}$ 7.4) for $1 \mathrm{~h}$, followed by incubation with primary antibody (1:1000) overnight at $4^{\circ}$. After incubation with horseradish peroxidase-conjugated secondary antibody (1:5000) for $1 \mathrm{~h}$ at room temperature, the bands were developed with Super Signal West Femto Maximum Sensitivity Substrate (Pierce Biotechnology) and imaged with the ChemiDoc $^{\text {TM }}$ MP Imaging System (BioRad, Hercules, CA, USA).

LO2 cells were treated with OA for $6 \mathrm{~h}$ followed by incubation with DMEM containing Hoechst 33342 / PI (1:1000) solution for $10 \mathrm{~min}$ at room temperature and observed under a microscope. The significance of differences between groups was evaluated by twoway analysis of variance (ANOVA) using GraphPad Prism 6.0 (GraphPad Software, Inc., La Jolla, CA). The $p$ value $<0.05$ was considered statistically significant.

As shown in fig. $1 \mathrm{~A}, \mathrm{OA}$ at $20 \mu \mathrm{M}$ showed no effect on the cell viability of LO2 cells. However, OA significantly decreases LO2 cell viability at 40 and $80 \mu \mathrm{M}$. Especially, the cell viability decreased to $20 \%$ of the control after $12 \mathrm{~h}$ of $80 \mu \mathrm{M}$ OA treatment. The cytotoxic effect of OA was further confirmed by determining the intracellular ATP levels. OA treatment dramatically depleted intracellular ATP content (fig. 1B). In addition, $20 \mu \mathrm{M}$ OA treatment showed no effect on the morphology of LO2 cells. However, $40 \mu \mathrm{M}$ OA treatment caused cell swelling, transparence of cytoplasm, and membrane bubbles. While $80 \mu \mathrm{M}$ OA induced cell membrane shrinking, which was totally different form the morphology induced by $40 \mu \mathrm{MOA}$ (fig. 1C). This result indicated that different concentrations of OA induced different kinds of cell death. Fig. 2A depicts the flow cytometry results of Annexin $\mathrm{V} / 7$-AAD double staining assay. Low concentration of OA $(40 \mu \mathrm{M})$ induced increase in Annexin V positive cells. The apoptotic cells rate was about $54 \%$. Similarly, $200 \mu \mathrm{M}$ cisplatin also induced dramatic apoptotic cell death. Furthermore, OA treatment induced significant cleavages of caspase 3/7/9 in a time-dependent manner (fig. 2B). Z-VAD-FMK, a cell-permeable pan-caspase inhibitor, significantly reversed the cell death induced 
by $40 \mu \mathrm{M}$ OA (fig. 2C). In addition, as shown in fig. 2D, the MMP level of LO2 cells decreased in a timedependent manner after OA treatment. The cytotoxic effect of OA at $80 \mu \mathrm{M}$ was determined. As shown in fig. 3A, $80 \mu \mathrm{M}$ OA induced rapid cell death in a timedependent manner. In the Annexin-V and 7AAD double staining assay, $80 \mu \mathrm{M}$ OA treatment for $6 \mathrm{~h}$ showed significant increase of 7-AAD positive cells (fig. 3B). Hoechst 33342/PI staining results showed that there was no PI positive cells in the control group while in the OA-treated group the number of PI positive cells greatly increased. Simultaneously, Hoechst 33342 staining showed no sign of nuclear condensation and DNA fragmentation (fig. 3C). Furthermore, Z-VADFMK pretreatment significantly reversed $40 \mu \mathrm{M}$ OAinduced cell death (fig. 2C) but showed no effect on $80 \mu \mathrm{M}$ OA-induced cells death (fig. 3D). In addition, Western blotting showed increased expression of cleaved caspase $3 / 7$ in $40 \mu \mathrm{M}$ OA and cisplatin-treated LO2 cells while $80 \mu \mathrm{M}$ OA treatment showed no effect
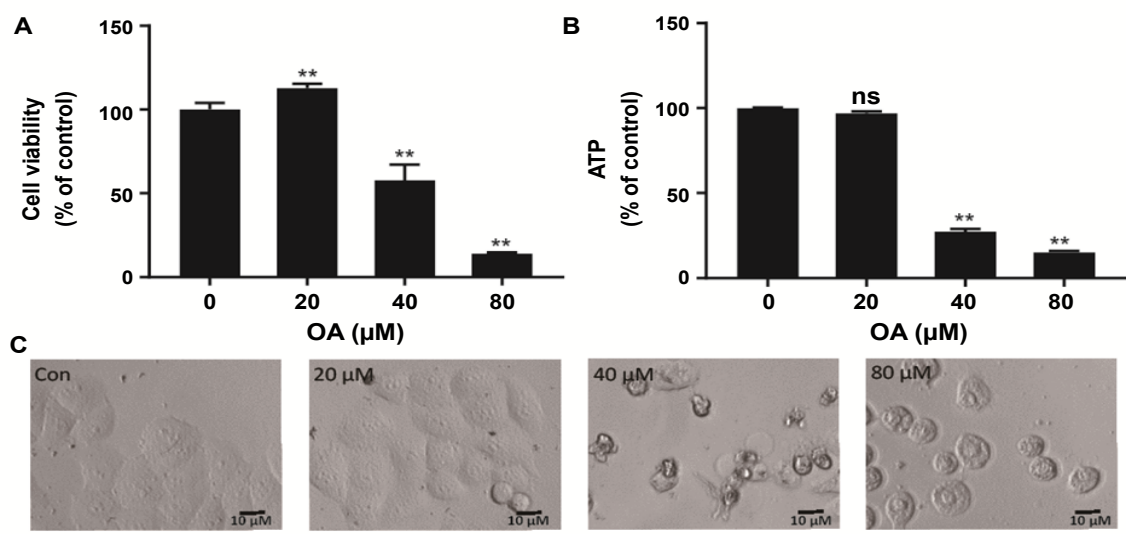

Fig. 1: The cytotoxic effect of OA on $\mathrm{LO} 2$ cells

LO2 cells were treated with OA for $24 \mathrm{~h}$ and A. cell viability was determined using MTT assay, B. intracellular ATP level was determined with a commercial kit and $C$. cell morphologies were captured by IN Cell Analyzer 2000. Data were presented as percent of control. ${ }^{* * *} p<0.05$ vs cells in control group. OA is oleanolic acid
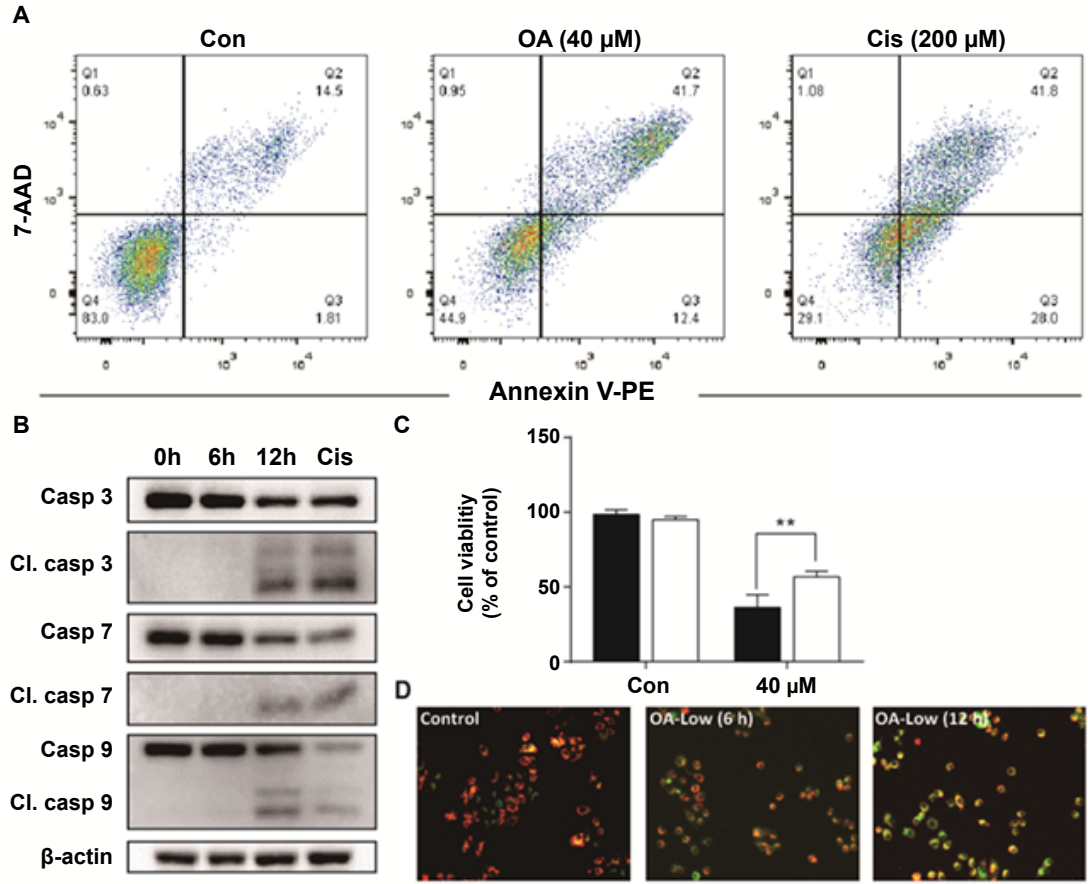

Annexin V-PE
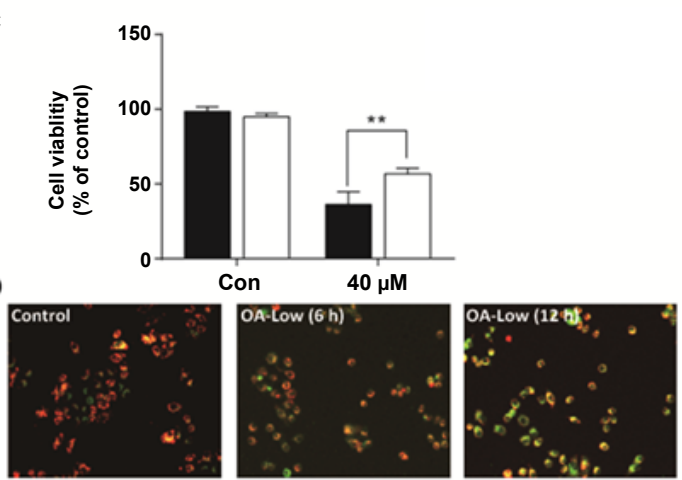

Fig. 2: Low concentration of $\mathrm{OA}$ induces apoptosis in $\mathrm{LO} 2$ cells

A. LO2 cells were treated with OA $(40 \mu \mathrm{M})$ for $24 \mathrm{~h}$ and apoptosis was determined using flow cytometry. B. Cells were treated with $40 \mu \mathrm{M} O A$ for 8 and $16 \mathrm{~h}$ and the protein expression was analyzed using Western blot. C. LO2 cells were pretreated with Z-VAD-FMK $(20 \mu \mathrm{M})$ for $1 \mathrm{~h}$ followed by $40 \mu \mathrm{M}$ OA treatment for $24 \mathrm{~h}$. Cell viability was determined using the MTT assay. ${ }^{* *} p<0.05$ vs cells treated with $40 \mu$ M OA alone. D. LO2 cells were treated with OA (40 $\mu$ M) for 6 and $12 \mathrm{~h}$. The mitochondrial membrane potential reduction was detected by JC-1 staining. OA is oleanolic acid. ( $\square$ ) Z-VAD-FMK (0 $\mu M)$, () Z-VAD-FMK (20 $\boldsymbol{\mu M})$ 
on the cleaved caspase 3/7 (fig. 3E). Western blotting results showed that $80 \mu \mathrm{M}$ OA treatment significantly increased protein expression of phosphorylated RIPK1 and RIPK-3 at Ser166 and Ser227, respectively (fig. 4A). However, neither Nec-1s nor GSK'872 have demonstrated protective effect against $80 \mu \mathrm{M}$ OAinduced cell death (fig. 4B). NAC had no significant effect on OA induced cell death at both concentrations (fig. 5A and 5B). Furthermore, the intracellular ROS generation as determined using fluorescence probe $\mathrm{DCFH}_{2}$-DA also showed that OA treatment showed no effect on ROS production in LO2 cells after 2 and $4 \mathrm{~h}$ treatment (fig. 5C).
The hepatoprotective effect of OA has been investigated for many years and OA has been widely used as adjuvant therapy for acute and chronic hepatitis. However, it was recently observed that high dosage and long duration of OA treatment could induce liver injury in experimental mice ${ }^{[17,18]}$. Furthermore, this paradoxical hepatotoxic effect occurs not only for OA, but also for other OA-type triterpenoids ${ }^{[19]}$. Thus, in the present study, the cytotoxic effect of OA on LO2 hepatocytes were determined. The main findings of this study were, low concentration of OA $(40 \mu \mathrm{M})$ induced caspasedependent apoptosis while higher concentration of OA $(80 \mu \mathrm{M})$ produced necrosis in LO2 cells. OA-induced
A

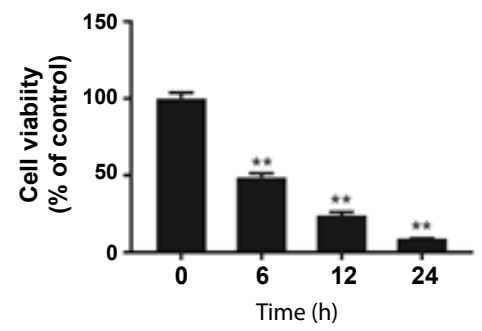

C
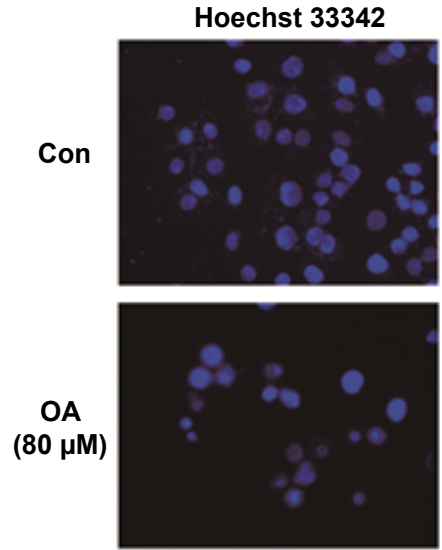

D

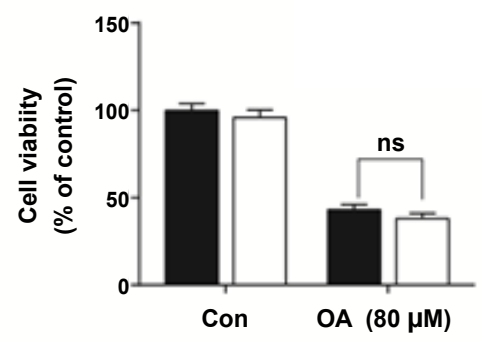

B

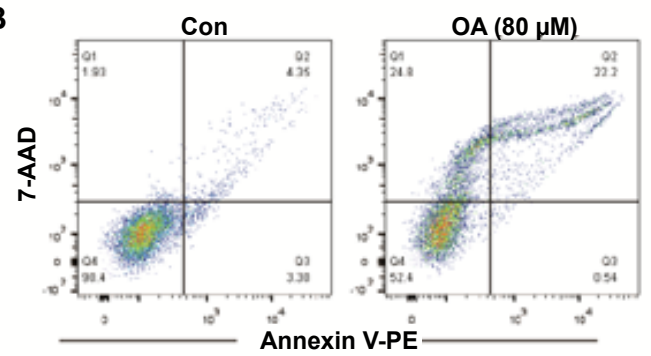

PI
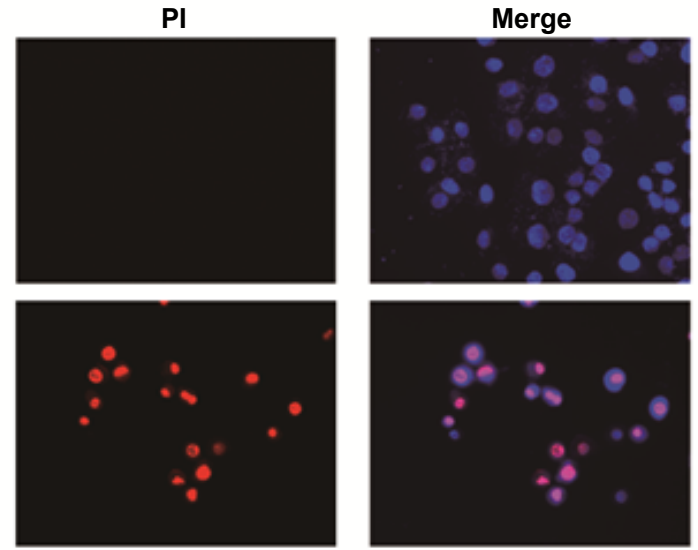

E

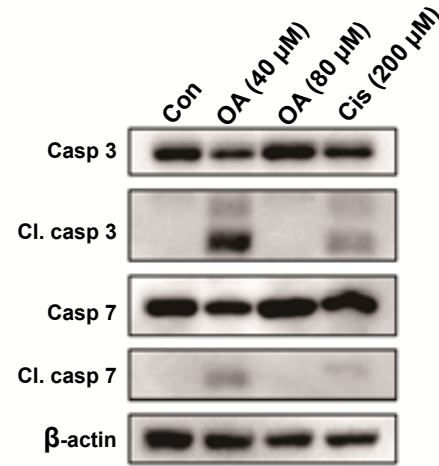

Fig. 3: High concentration of $\mathrm{OA}$ induces non-apoptotic cell death

A. LO2 cells were treated with OA $(80 \mu \mathrm{M})$ for 6,12 and $24 \mathrm{~h}$ and cell viability was determined using the MTT assay. ${ }^{* *} p<0.01$ vs cells of the control group. B. LO2 cells were treated with $80 \mu \mathrm{M} O A$ for $6 \mathrm{~h}$ and the cell death was analyzed with Annexin V (PE)/7AAD double staining by flow cytometry. C. LO2 cells were treated with OA (80 $\mu$ M) and Hoechst 33342/PI staining was performed. D. LO2 cells were pretreated with Z-VAD-FMK $(20 \mu M)$ for $1 \mathrm{~h}$ followed by OA $(80 \mu \mathrm{M})$ and cell viability was measured 6 h later with MTT assay. E. Cells were treated with $40 \mu \mathrm{M}$ OA for 16 h or 80 $\mu \mathrm{M} O A$ for $2 \mathrm{~h}$ and the protein expression was detected using Western blotting. OA is oleanolic acid; PI is propidium iodide. ( $\square$ ) Z-VAD-FMK (0 $\mu M)$, ( $(\mathrm{)}) \mathrm{Z}$-VAD-FMK (20 $\mu \mathrm{M})$ 

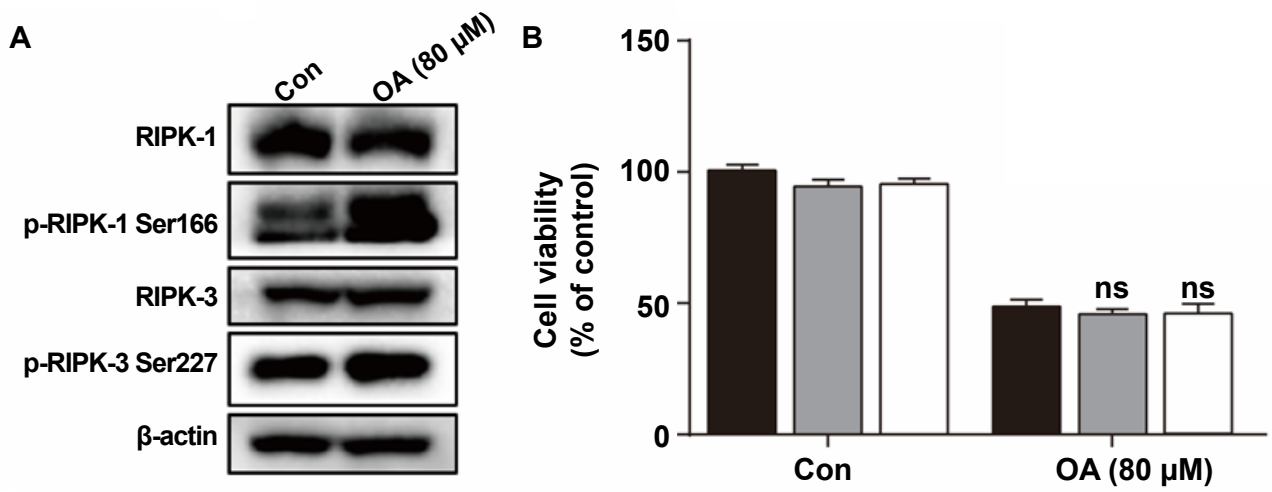

Fig. 4: High concentration of $\mathrm{OA}$ induced $\mathrm{LO} 2$ cell death but not necroptosis

A. Cells were treated with $\mathrm{OA}(80 \mu \mathrm{M})$ for $2 \mathrm{~h}$ and the protein expression was detected using Western blotting. B. LO2 cells were pretreated with Nec-1s $(20 \mu \mathrm{M})$ and GSK'872 $(5 \mu \mathrm{M})$ for $1 \mathrm{~h}$ followed by OA $(80 \mu \mathrm{M})$ for $6 \mathrm{~h}$ and cell viability was measured with MTT assay. OA is oleanolic acid; Nec-1s is necrostatin-1s. ( 1$)$ DMSO, ( $\square)$ Nec-1s(20 $\mu \mathrm{M})$, (口) GSK'872 (5 $\mu \mathrm{M})$
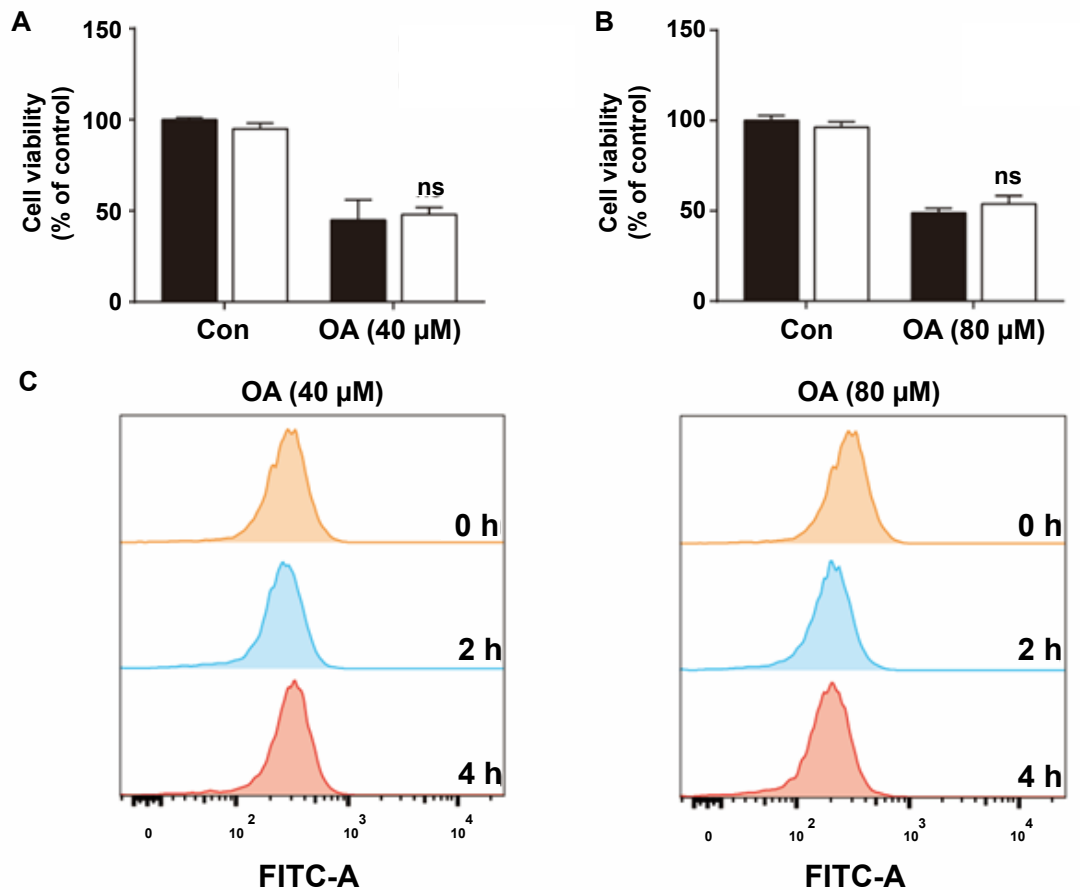

Fig. 5: Effect of OA on intracellular ROS generation in LO2 cells

A. LO2 cells were pretreated with NAC $(4 \mathrm{mM}) 1 \mathrm{~h}$ followed by OA $(40 \mu \mathrm{M})$ for $24 \mathrm{~h}$ or OA $(80 \mu \mathrm{M})$ for $6 \mathrm{~h}$. Cell viability was measured using MTT assay. B. LO2 cells were treated with 40 and $80 \mu M$ OA for 2 and $4 \mathrm{~h}$, respectively and intracellular ROS levels were determined by flow cytometry with the fluorescent probe $\mathrm{DCFH}_{2}-\mathrm{DA}$. OA is oleanolic acid; ROS is reactive oxygen species. (घ) NAC (0 mM), () NAC (4 mM)

cell death was ROS independent. OA has been reported to induce apoptosis in human hepatocellular carcinoma cells $^{[21,22]}$, non-small cell lung cancer cell lines ${ }^{[23]}$, hypertrophic scar fibroblasts ${ }^{[24]}$ and osteosarcoma cells $^{[25]}$. In this investigation it was found that OA could decrease LO2 cell viability in a concentration-dependent manner. Annexin-V and 7AAD double staining showed that $\mathrm{OA}(40 \mu \mathrm{M})$ treatment induced apoptosis in LO2 cells. This was further confirmed by the cleavage of caspase 3/7/9 and decrease of MMP. Furthermore, $\mathrm{OA}$-induced cell death was significantly reversed by
Z-VAD-FMK, a pan-caspase inhibitor, suggesting that OA-induced cell death was caspase-dependent. Thus, these results showed that low concentration of OA induced caspase-dependent apoptosis in LO2 cells. Necrosis was generally considered as an unregulated type of cell death in response to external factors such as trauma or infection. However, recent studies revealed that necroptosis was a programmed necrosis mediated by RIP1, RIP3, and MLKL ${ }^{[26]}$. A series of natural products such as shikonin ${ }^{[27]}$, 2-methoxy-6acetyl-7-methyljuglone ${ }^{[28]}$ have been reported to induce 
necroptosis in cancer cells. High concentration of OA induced necrotic morphologies. The penetration of PI into the cytoplasm suggested that the integration of cell membrane was disturbed. Furthermore, OA showed no effect on the cleavage of caspases and Z-VAD-FMK showed no effect on OA-induced cell death. These results suggested that OA produced nonapoptotic necrosis in LO2 cells. Although OA caused phosphorylation of RIP1 and RIP3, the inability of Nec-1s and GSK'872, the specific inhibitors of RIP1 and RIP3, respectively, suggested that OA-induced cell death was RIPs-independent. Collectively, these data revealed that OA caused non-apoptotic necrosis in $\mathrm{LO} 2$ cells. ROS has been implicated to play critical roles in OA-induced cell cycle arrest, apoptosis, and autophagic cell death in human pancreatic cancer cells ${ }^{[29]}$, A549 lung cancer cells ${ }^{[30]}$, and hepatocellular carcinoma cells $^{[31]}$. However, in the current investigation it was observed that both concentrations of OA showed no effect on intracellular ROS generation. Furthermore, $\mathrm{NAC}$, the ROS scavenger, failed to protect $\mathrm{LO} 2$ cells from OA-induced cell death. Thus, it seems that OA's effects on $\mathrm{LO} 2$ cells were different from those in cancer cells, OA-induced apoptosis and necrosis was ROSindependent. In conclusion, OA, a hepatoprotective natural product, induced caspase-dependent apoptosis and necrosis in LO2 cells. These results suggested that clinical application of OA might injure hepatocytes and the dosages and duration should be tightly controlled in clinical practice.

\section{Acknowledgments:}

This study was supported by the Science and Technology Development Fund of Macau Special Administrative Region (FDCT) (078/2016/A2, 175/2017/A3) and the Research Fund of University of Macau (MYRG201600043-ICMS-QRCM).

\section{Conflicts of interest:}

The authors declare no conflict of interest.

\section{REFERENCES}

1. Chalasani N, Fontana RJ, Bonkovsky HL, Watkins PB, Davern $\mathrm{T}$, Serrano J, et al. Causes, clinical features, and outcomes from a prospective study of drug-induced liver injury in the United States. Gastroenterology 2008;135:1924-34.

2. Teschke R, Larrey D, Melchart D, Danan G. Traditional Chinese Medicine (TCM) and Herbal Hepatotoxicity: RUCAM and the Role of Novel Diagnostic Biomarkers Such as MicroRNAs. Medicines (Basel) 2016;19(3):E18.

3. You Y, Li JR, Huang FH, Han L. Relationship between preclinical toxicity and efficacy of traditional Chinese medicine. Zhongguo Zhong Yao Za Zhi 2017;42:4045-48.

4. Xu LM, Lin QX. Hepatic toxicity of Chinese herbal medicine.
Zhonghua Gan Zang Bing Za Zhi 2007;15:534-5.

5. Wang R, Qi X, Yoshida EM, Mendez-Sanchez N, Teschke R, Sun M, Liu X, Su C, Deng J, Deng H, Hou F, Guo X. Clinical characteristics and outcomes of traditional Chinese medicine-induced liver injury: a systematic review. Expert Rev Gastroenterol Hepatol 2018;12:425-34.

6. Teschke R, Wolff A, Frenzel C, Schulze J. Review article: Herbal hepatotoxicity--an update on traditional Chinese medicine preparations. Aliment Pharmacol Ther 2014;40:3250.

7. Pollier J, Goossens A. Oleanolic acid. Phytochemistry 2012;77:10-15.

8. Shanmugam MK, Dai X, Kumar AP, Tan BK, Sethi G, Bishayee A. Oleanolic acid and its synthetic derivatives for the prevention and therapy of cancer: preclinical and clinical evidence. Cancer Lett 2014;346:206-16.

9. Ziberna L, Samec D, Mocan A, Nabavi SF, Bishayee A, Farooqi AA, et al. Oleanolic Acid Alters Multiple Cell Signaling Pathways: Implication in Cancer Prevention and Therapy. Int J Mol Sci 16 2017;18.

10. Castellano JM, Guinda A, Delgado T, Rada M, Cayuela JA. Biochemical basis of the antidiabetic activity of oleanolic acid and related pentacyclic triterpenes. Diabetes 2013;62:1791-9.

11. Silva FS, Oliveira PJ, Duarte MF. Oleanolic, Ursolic, and Betulinic Acids as Food Supplements or Pharmaceutical Agents for Type 2 Diabetes: Promise or Illusion? J Agric Food Chem 2016;64:2991-3008.

12. Kashyap D, Sharma A, Tuli HS, Punia S, Sharma AK. Ursolic Acid and Oleanolic Acid: Pentacyclic Terpenoids with Promising Anti-Inflammatory Activities. Recent Pat Inflamm Allergy Drug Discov 2016;10:21-33.

13. Khwaza V, Oyedeji OO, Aderibigbe BA. Antiviral Activities of Oleanolic Acid and Its Analogues. Molecules 2018;23.

14. Sultana N, Ata A. Oleanolic acid and related derivatives as medicinally important compounds. J Enzyme Inhib Med Chem 2008;23:739-56.

15. Liu J, Liu Y, Madhu C, Klaassen CD. Protective effects of oleanolic acid on acetaminophen-induced hepatotoxicity in mice. J Pharmacol Exp Ther 1993;266:1607-13.

16. Nyakudya TT, Mukwevho E, Nkomozepi P, Erlwanger KH. Neonatal intake of oleanolic acid attenuates the subsequent development of high fructose diet-induced non-alcoholic fatty liver disease in rats. J Dev Orig Health Dis 2018;9:500-10.

17. Lu YF, Wan XL, Xu Y, Liu J. Repeated oral administration of oleanolic acid produces cholestatic liver injury in mice. Molecules 2013;18:3060-71.

18. Liu J, Lu YF, Zhang Y, Wu KC, Fan F, Klaassen CD. Oleanolic acid alters bile acid metabolism and produces cholestatic liver injury in mice. Toxicol Appl Pharmacol 2013;272:816-24.

19. Liu J, Lu YF, Wu Q, Xu SF, Shi FG, Klaassen CD. Oleanolic acid reprograms the liver to protect against hepatotoxicants, but is hepatotoxic at high doses. Liver Int 2019;39(3):427-39.

20. Malhi H, Guicciardi ME, Gores GJ. Hepatocyte death: a clear and present danger. Physiol Rev 2010;90:1165-94.

21. Shyu MH, Kao TC, Yen GC. Oleanolic acid and ursolic acid induce apoptosis in $\mathrm{HuH7}$ human hepatocellular carcinoma cells through a mitochondrial-dependent pathway and downregulation of XIAP. J Agric Food Chem 2010;58:611018.

22. Yan SL, Huang CY, Wu ST, Yin MC. Oleanolic acid and ursolic acid induce apoptosis in four human liver cancer cell lines. Toxicol In Vitro 2010;24:842-848.

23. Lucio KA, Rocha Gda G, Moncao-Ribeiro LC, Fernandes J, 
Takiya CM, Gattass CR. Oleanolic acid initiates apoptosis in non-small cell lung cancer cell lines and reduces metastasis of a B16F10 melanoma model in vivo. PLoS One 2011;6e28596.

24. Chen JY, Zhang L, Zhang H, Su L, Qin LP. Triggering of p38 MAPK and JNK signaling is important for oleanolic acidinduced apoptosis via the mitochondrial death pathway in hypertrophic scar fibroblasts. Phytother Res 2014;28:1468-78.

25. Xu Y, Shu B, Tian Y, Wang G, Wang Y, Wang J, et al. Oleanolic acid induces osteosarcoma cell apoptosis by inhibition of Notch signaling. Mol Carcinog 2018;57:896-902.

26. Vandenabeele P, Galluzzi L, Vanden Berghe T, Kroemer G. Molecular mechanisms of necroptosis: an ordered cellular explosion. Nat Rev Mol Cell Biol 2010;11:700-14.

27. Fu Z, Deng B, Liao Y, Shan L, Yin F, Wang Z, et al. The antitumor effect of shikonin on osteosarcoma by inducing RIP1 and RIP3 dependent necroptosis. BMC Cancer 2013;13:580.

28. Sun W, Bao J, Lin W, Gao H, Zhao W, Zhang Q, et al.
2-Methoxy-6-acetyl-7-methyljuglone (MAM), a natural naphthoquinone, induces NO-dependent apoptosis and necroptosis by $\mathrm{H} 2 \mathrm{O} 2$-dependent $\mathrm{JNK}$ activation in cancer cells. Free Radic Biol Med 2016;92:61-77.

29. Wei J, Liu M, Liu H, Wang H, Wang F, Zhang Y, et al. Oleanolic acid arrests cell cycle and induces apoptosis via ROS-mediated mitochondrial depolarization and lysosomal membrane permeabilization in human pancreatic cancer cells. J Appl Toxicol 2013;33:756-65.

30. Liu J, Wu N, Ma LN, Zhong JT, Liu G, Zheng LH, et al. p38 MAPK signaling mediates mitochondrial apoptosis in cancer cells induced by oleanolic acid. Asian Pac J Cancer 2014;15:4519-25.

31. Shi Y, Song Q, Hu D, Zhuang X, Yu S, Teng D. Oleanolic acid induced autophagic cell death in hepatocellular carcinoma cells via PI3K/Akt/mTOR and ROS-dependent pathway. Korean J Physiol Pharmacol 2016;20:237-43. 